\title{
Polysensitivity to Anti-Leprosy Drugs
}

S. G. BROWNE, M.D., F.R.C.P., F.R.C.S., D.T.M.

I.eprosy Service Research Unit, Uzuakoli, Eastern Nigeria

During the past five years, I 3 leprosy patients at Uzuakoli, who exhibited discrete or diffuse fixed eruptions induced by standard dapsone medication, experienced recurrent exacerbation of the eruption when another anti-leprosy drug was given, some of them also proving sensitive to other drugs as well.

Polysensitivity, or parallergic sensitivity, is a phenomenon that has long been recognized by dermatologists in respect of sulphonamides, barbiturates, and many other chemically related groups of drugs. Heterocyclic sensitivity is a less common condition characterized by sensitivity to drugs of totally different chemical constitution from that which induces the fixed eruption. More rarely, non-specific physical factors such as heat or cold or light, or endogenous products of tissue breakdown as in menstruation and fever, may precipitate an exacerbation of a fixed eruption whatever the chemical nature of the inducing drug.

\section{SENSITIZING DRUG}

In all I 3 Uzuakoli patients the sensitizing drug was dapsone, but the duration of treatment, and consequently the total amount of drug given before the appearance of the fixed eruption, varied within very wide limits.

In three patients, the first dose of dapsone (0.05 or o. I o gm.) precipitated localized or generalized pruritus followed after a variably short interval by the characteristic discrete hypermelanotic macules of fixed eruptions in deeply-pigmented subjects, or by a diffuse hypermelanosis of the pruritic skin. Parallergic sensitivity following primary sensitization to a drug other than dapsone (e.g. a sulphonamide) - which might explain the rapid appearance of dapsone-sensitivity after the very first dose of dapsone - could be excluded by demonstrating that these patients were not sensitive to sulphonamides. In another patient, the fixed eruption appeared in the fourth week of treatment: for the first three weeks o. I gm. had been given twice weekly, the discrete pruritus and fixed eruption appearing immediately after the first dose of $0.2 \mathrm{gm}$. Another patient, in whom an initial dose of o. I gm. given under medical supervision precipitated a fixed eruption, subsequently confessed to selfmedication with illicitly purchased dapsone six months before. He had taken $0.3 \mathrm{gm}$. daily for six weeks before experiencing a typical sixth-week high-dose-dapsone exfoliative dermatitis, from which he fortunately recovered. The other patients had all taken standard doses of dapsone for many months - up to two years - without untoward effect, before experiencing pruritus of sudden onset, followed by the typical fixed eruption. 
THE PATIEN'TS

All is patients were adults; there were eight males and five females. Their ages ranged from 20 to 65 years, with an average of about 36 years. All forms of leprosy were represented among them, and this group differed in no way from any other group comparable in age under treatment for leprosy at Uzuakoli. 'The only noticeable feature was the absence of children in the group. (A boy of six years of age has been seen recently in whom a typical fixed eruption induced by chloroquine underwent exacerbation on each subsequent administration of amodiaquinc).

GROUP SENSITIVITY

Chemically related drugs may in certain patients act preciscly as the inducing drug in precipitating exacerbation of the fixed eruption. In this series, during slow desensitization following the standard procedure (Browne, r 963), three patients showed sensitivity to minute doses of solapsone (Sulphetrone, Burroughs Wellcome) taken orally. Three were sensitive also to diamino-diphenyl sulphoxide (BROWNE and DAVEY, I 962), two of them experiencing an exacerbation after taking a first dose of o. $10 \mathrm{gm}$. of the drug, and the other after 23 months' continuous treatment with the drug at $0.3 \mathrm{gm}$. twice weckly.

In two patients, sulphonamides (drugs less closely related chemically to dapsone) precipitated an exacerbation of the fixed eruption. These drugs were sulphathiazole and sulphadimidine, prescribed for intercurrent infections.

\section{HETER OCYCILIC SENSITIVITY}

In some patients, drugs used in leprosy treatment and chemically unrelated to dapsone, proved equally potent in reactivating dapsone-induced fixed eruptions. Thus, five patients proved sensitive also to thiambutosine (a diphenyl thiourea, Ciba I 9o6), and threc to thiacetazone (TB I).

Threc patients with dapsone-induced eruptions were sensitive also to other sulphones, to thiambutosine, and to thiacetazone: two of them were sensitive to ditophal (Etisul, I.C.I.) and to antihistaminics which were given therapeutically to control the severe skin eruptions. Furthermore, barbiturate sedatives caused immediate flare-up in the hypersensitive skin. It would appear that any drug or any substance apart from innocuous items of food habitually taken, might precipitate a reaction in such a skin.

In one of these patients, dermatitis recurred after a lapse of ten days even when no drugs at all were being taken, recalling the recurrent ten-day exaccrbation in erythema multiforme resulting probably from endogenous tissuc breakdown.

\section{DESENSI T I Z A T I O N}

Five of the I 3 patients who have proved sensitive to other anti-leprosy drugs, were successfully desensitized (BROWNE, I 963 ). One of these subsequently developed a diffuse hypermelanosis of the lower abdomen and the beard area which began to aprear after two months' treatment with 
dapsone, $0.05 \mathrm{gm}$. twice weckly, and which gradually increased in intensity without symptoms of pruritus.

\section{$S U M M A R Y$}

In 13 adults under treatment for leprosy, dapsone-induced fixed eruptions underwent exacerbation when the patients were given other sulphones, or other anti-leprosy drugs unrelated chemically to the sulphones. Some were also sensitive to sulphonamides, and three were sensitive also to antihistaminics and barbiturates.

\section{A C K N OWLEDGEMENT}

My thanks are due to Dr. s. O. Egwuntu, Chief Medical Officer, Minister of Health, Eastern Nigeria, for permission to publish this article.

\section{References}

BROWNE, S. (.. (1963) Brit. med. J., 2, 664.

BROWNE, s. (i. and DAVEY, T. F. (1962) Leprosy Rev., 32, 194. 